\title{
Self-medication Practice among Health Sciences Undergraduate Students in Sana'a City-Yemen
}

\author{
Doa'a Anwar Ibrahim*, Abdulsalam Halboup \\ Department of Clinical Pharmacy and Pharmacy Practice, Faculty of Pharmacy, University of Science and Technology, Sana'a, YEMEN.
}

\begin{abstract}
Background: The self-medication practice (SM) has increased worldwide for treating mild ailments without medical consultation and drug prescription. Health information background and proper SM may have positive outcomes. This study is focused on the SM practice among the undergraduate health science students either medicine or paramedical students in different education levels in Sana'a City. Methods: A prospective crosssectional questionnaire was structured and validated to conduct randomly a sample of health science undergraduate students from January to April 2019 in Sana'a City-Yemen. Chi-square test and logistic regressions were the analytical methods used in this study. A 468-health science students involved in this study for 4 months form from January 2019 to April 2019. Results: The prevalence of SM practice was $90 \%$ compared with non-selfmedicating respondents $(10 \%)$ as outcomes of this work. Females $(93 \%)$ showed significantly higher SM practice than males (87\%). The mildness of the illness $(90 \%)$ and prior experience $(82 \%)$ were the two most frequently reported source of drug information for self-medication in this study. Cough, common cold $(88 \%)$ and headache $(88 \%)$ were the most likely symptoms reported as self-medicated illnesses in the present study.
\end{abstract}

The most frequently consumed medications have been analgesics $(87 \%)$, common cold preparations (82\%) and antipyretics (78\%). Self-medication practice was noticeable among health sciences undergraduate students in Sana'a city and this referred to the mildness of the illness and previous experience. There were statistically significant differences between respondents based on gender in the present study, but there were differences, neither according to specific fields nor to educational level.

Key words: Self-medication, Health sciences students, Questionnaire, Sana'a City, Yemen.

\section{Correspondence}

Dr. Doa'a Anwar, (Ph.D)

Professor, Department of Clinical Pharmacy and Pharmacy Practice, Faculty of Pharmacy, University of Science and Technology, Sana'a, YEMEN.

Phone no: +967 733308292

Email: dr_d_anwar@hotmail.com

DOI: 10.5330/ijpi.2019.2.16

\section{INTRODUCTION}

Medicines design and use for the mitigation, prevention and treatment of different ailments. According to FDA classification, the medicines are present in two regulatory forms either prescribed drugs or over the counter drugs (OTC). ${ }^{1}$ However, OTC drug products are effective and safe used for the mild illness, not need a prescription or health care supervision thus recent buildup and encourage the self-medication practice among people. World Health Organization accepted and encourages the use of SM practice as a part of self-care especially in poor countries or areas with limited health service. ${ }^{2}$ Moreover, self-care is known as what people do by themselves to inaugurate and maintain health, preventing and dealing with the disease. This concept of self-care includes health, nutrition, lifestyle, socioeconomic and environmental factors, as well as self-medication. ${ }^{3}$ Nowadays, self-medication is widely practiced among people around the world, this may refer to the treatment of minor illness, less costly, prior experience or saving time or they have insufficient time to visit doctors. ${ }^{4}$ Self-medication has many hazards ranged from inaccurate self-diagnosis, prolonged use, the emergence of pathogen resistance, adverse drug reaction, drug and food interactions as well as dependence. ${ }^{5,6}$ Contradictory, if SM is based on proper practiced and health information, the outcomes can be positively in saving lives, time and money, especially in some minor ailments that not need medical consultation. ${ }^{7}$ The prevalence of SM practice was found to vary among people, particularly medical students of different countries in different studies. In a study carried out by 1296 medical students at the University of Belgrade in 2014, the prevalence of SM was reported 79.9\%. ${ }^{8}$ However, an additional study done in Turkey showed that prevalence among 960 medical students to be $63.4 \% .{ }^{9}$ Even though, SM practice may depend on the level of undergraduate medical students. ${ }^{10,11}$ According to the worldwide increasing of SM either in urban and rural areas, previous studies were done in Yemen, Saudi Arabia and Uzbekistan focused on the SM of antibiotics and using of different medications among consumers. ${ }^{12,13}$ The most common reasons for SM in different studies were headache, pain and common cold and the most prevalent medications used analgesics, antipyretic and common cold preparation. ${ }^{14,15}$ The main objective of this study is to assess the prevalence of SM practice among undergraduate health science (medical and paramedical) students in Sana'a City -Yemen.

\section{METHODS}

\section{Ethics approval and consent}

Ethical approval by the University Ethics Committee (No. EAC/UST 160 ) at the University of Science and Technology (UST), Sana'a-Yemen was done before commencing steps of this study. It was declared to all participants that they were free to fulfill the questionnaire as volunteers and all information was kept confidential.

\section{Study design}

A prospective, cross-sectional descriptive study, questionnaire containing open-ended and close-ended items for data collection were used in this study. 


\section{Study population and sampling}

There were a total of 468 health science students participated in this study. They were chosen as a sample size from the two biggest universities in Sana'a city, the Capital of the Republic of Yemen according to the Ministry of Higher Education resources. These universities were classified according to the number of students and different health science specialties (one private: University of Science and Technology (UST) and the other was the government university: Sana'a University). The students were selected randomly from different health science education levels and different specialties, medicine and paramedical students (pharmacy, dentistry and other health science specialties like radiology, laboratories, nutrition) as inclusion criteria. Graduated students or postgraduate students were excluded from this study.

\section{Study tools}

Structure validated and pretested questionnaire from Community medicine department at UST were classified into two sections. The first one consisted of demographic information including age, sex and marital status, the field of study, graduation level and location. The second section focused on the diseases and ailments that lead to SM practice, classes of medications that mostly used as SM and the reasons behind
SM practice. $5 \%$ of this questionnaire were distributed for all students at a different level to avoid bias.

\section{Study area and duration}

This study was conducted on the Health Science campus at the University of Science Technology found in Sana'a City the Capital of the Republic of Yemen. The health science campus includes the College of Medicine and Health Sciences, College of Pharmacy and finally the College of Dentistry. The data collection period was continued for 4 months from January 2019 to April 2019.

\section{Data Analysis}

The data obtained was analyzed by SPSS version 21 software using descriptive statistics (frequency, mean and standard deviation) and inferential statistics (a chi-square test and logistic regressions). To assess the association between SM and demographic characteristics, a chi-square test was chosen. The confidence interval $95 \%$ and $p<0.05$ were considered significant.

\section{RESULTS}

A total of 468 undergraduate health science students agreed to participate in this study to evaluate and assess SM practice. Table 1 shows the

Table 1: Socio-demographic characteristic of respondents by self-medication.

\begin{tabular}{|c|c|c|c|c|c|c|c|c|c|}
\hline \multirow{2}{*}{ Variables } & & \multicolumn{2}{|c|}{ Total } & \multicolumn{2}{|c|}{ Non Self-medicating } & \multicolumn{2}{|c|}{ Self-medicating } & \multicolumn{2}{|c|}{ Statistical tests } \\
\hline & & $\mathrm{N}$ & (\%) & $\mathrm{N}$ & $(\%)$ & $\mathrm{N}$ & (\%) & $\mathrm{X} 2$ & $P$-value \\
\hline \multirow[t]{3}{*}{ Gender } & & & & & & & & 4.604 & $0.032^{*}$ \\
\hline & Male & 200 & $(100 \%)$ & 26 & $(13 \%)$ & 174 & $(87 \%)$ & & \\
\hline & Female & 268 & $(100 \%)$ & 19 & $(7 \%)$ & 249 & $(93 \%)$ & & \\
\hline \multirow[t]{3}{*}{ Age } & & & & & & & & 0.864 & 0.718 \\
\hline & From $18-24$ & 444 & $(100 \%)$ & 44 & $(10 \%)$ & 400 & $(90 \%)$ & & \\
\hline & $\geq 25$ & 24 & $(100 \%)$ & 1 & $(4 \%)$ & 23 & $(96 \%)$ & & \\
\hline \multirow[t]{3}{*}{ Marital Status } & & & & & & & & 0.294 & 0.588 \\
\hline & Single & 415 & $(100 \%)$ & 41 & $(10 \%)$ & 374 & $(90 \%)$ & & \\
\hline & Married & 53 & $(100 \%)$ & 4 & $(8 \%)$ & 49 & $(92 \%)$ & & \\
\hline \multirow[t]{5}{*}{ Field of Study } & & & & & & & & 2.089 & 0.554 \\
\hline & Medicine & 171 & $(100 \%)$ & 15 & $(9 \%)$ & 156 & $(91 \%)$ & & \\
\hline & Pharmacy & 117 & $(100 \%)$ & 14 & $(12 \%)$ & 103 & $(88 \%)$ & & \\
\hline & $\begin{array}{l}\text { Other Health } \\
\text { Science }\end{array}$ & 55 & $(100 \%)$ & 7 & $(13 \%)$ & 48 & $(87 \%)$ & & \\
\hline & Dentistry & 120 & $(100 \%)$ & 9 & $(8 \%)$ & 111 & $(93 \%)$ & & \\
\hline \multirow[t]{6}{*}{ Education Level } & & & & & & & & 1.275 & 0.866 \\
\hline & First year & 97 & $(100 \%)$ & 12 & $(12 \%)$ & 85 & $(88 \%)$ & & \\
\hline & Second year & 120 & $(100 \%)$ & 10 & $(8 \%)$ & 110 & $(92 \%)$ & & \\
\hline & Third year & 113 & $(100 \%)$ & 10 & $(9 \%)$ & 103 & $(91 \%)$ & & \\
\hline & Fourth year & 68 & $(100 \%)$ & 7 & $(10 \%)$ & 61 & $(90 \%)$ & & \\
\hline & Fifth year & 70 & $(100 \%)$ & 6 & $(9 \%)$ & 64 & $(91 \%)$ & & \\
\hline \multirow[t]{3}{*}{ Location } & & & & & & & & 0.500 & 0.479 \\
\hline & Living with family & 353 & $(100 \%)$ & 32 & $(9 \%)$ & 321 & $(91 \%)$ & & \\
\hline & Dormitory & 115 & $(100 \%)$ & 13 & $(11 \%)$ & 102 & $(89 \%)$ & & \\
\hline
\end{tabular}

${ }^{*} p$-value is significant at $<0.05$. 
socio-demographic characteristics of the participants. SM practice according to the academic field, dentistry (93\%), medicine (91\%), pharmacy $(87 \%)$ and other health science $(88 \%)$. In terms of educational level, first- year (88\%), second-year (92\%), third-year (91\%), fourth-year (90\%) and fifth-year (91\%). Students living with their families showed higher (91\%) SM practiced than that living in the dormitory (89\%). The female showed significant SM practiced (93\%) than males (87\%), but there were no significant differences based on the academic field, level and location.

The symptoms of the mild illness as a source of SM practice were cough and common cold $88 \%$ this was the same rate of headache $(88 \%)$ followed by menstrual disorders (74\%) in female as shown in Figure 1.

Regarding the reasons for self-medication, the mildness of the illness (90\%) and prior experience (82\%) were the most likely reasons for SM practice among respondents in the current study as shown in Figure 2.

However, analgesics (87\%), common cold preparation (82\%) and antipyretics $(78 \%)$ were the most common medications used by participants according to the outcomes of the current work as shown in Figure 3.

\section{DISCUSSION}

Recently, many countries focused on the self-medication practice in their communities to detect the benefits or harmful effects of that practice and the types of illness used for as well as the classification of medications that are used in this case. When SM based on medical background, this formed a golden standard of self-care. ${ }^{1}$ In the present study the preva-

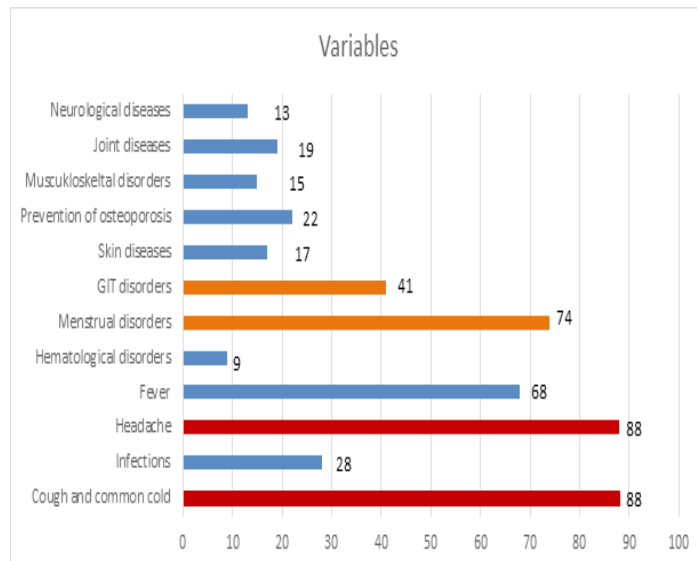

Figure 1: The most important Diseases/conditions, which lead to selfmedication.

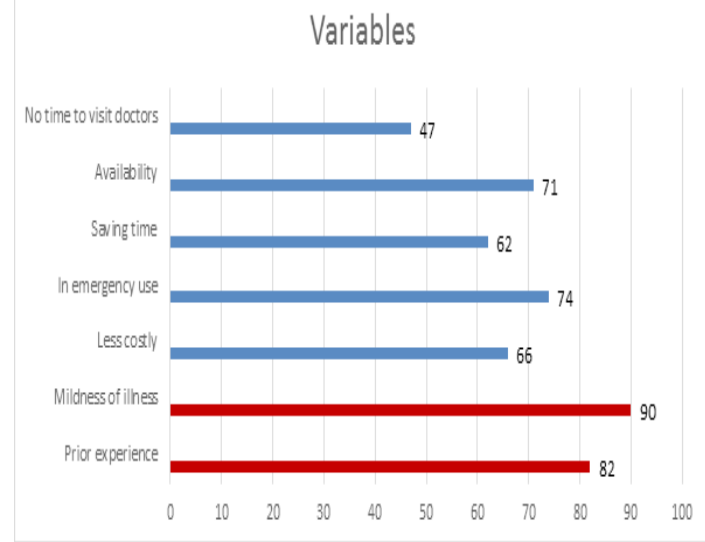

Figure 2: The most common reasons for self-medication.

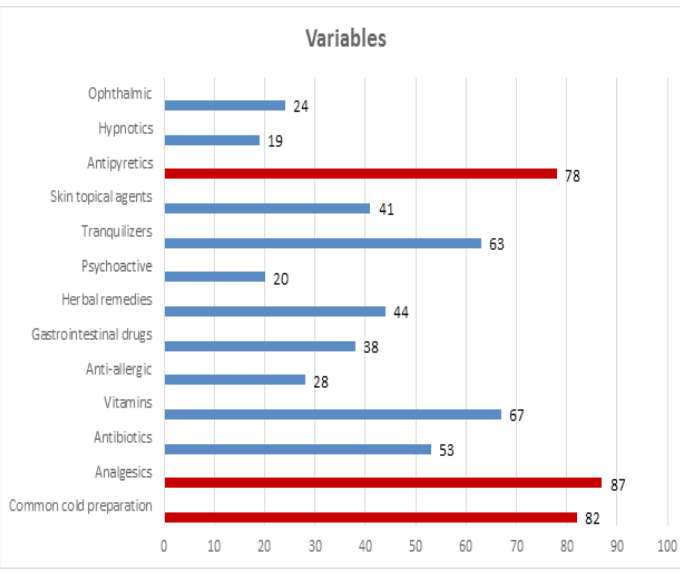

Figure 3: The most common Classes of Drugs used for Self-medications.

lence of SM practice was $90 \%$, which is a noticeable rate, compared with other studies conducted in different countries that ranged from $44.8 \%$ in Bahrain, Ain Shams University, Egypt, 55\%, Pakistan (76\%) and the closest prevalence outcomes were the studies done in Brazil $86.4 \%$ and Iran $89.9 \% .^{14,16-19}$ These variations in the rate of SM may refer to the difference in parameters of study research like study tools, the difference in demographic characteristics and selection of samples. Concerning Yemen as other developing countries, people have poor economic and costly health care facilities so the people try to treat their minor illnesses with freely available OTC medications. Indeed this interprets a steady and continuous increase SM practice in Yemen, particularly among school and university students taken into consideration many factors that may contribute to this practice; the first medication in our country is not covered by medical insurance. Secondly, there is no restricted control from health authorities for dispensing the medication or awareness campaign for the students or the public to improve their knowledge and attitude towards SM practice.

In the present study, the most prevalence of SM was among female students, $93 \%(n=249)$ which showed significant SM practice compared with male students $87 \%(n=174)$ according to demographic information with $(p=0.032)$. This finding agreed with Al Raddadi et al. 2018 who found that SM practice among female 54.02\% $(n=311)$ undergraduate students of King Saud University was more than male $45.18 \%(n=166)$ but insignificantly. ${ }^{20}$ Another study carried out in South India found that a larger number of females were self-medicating $(81.2 \%)$ than males $(75.3 \%) .{ }^{21}$ Additionally, another cross-sectional study of sex differences in self-medication practices among university students carried out in Slovenia showed that SM practice among females (94\%) was more than among males (90\%). ${ }^{22}$ Immune disturbance and hormonal changes in females especially prior to the time of menstruation exposed them to mild illness, particularly common cold and headache as well as the other symptoms of the premenstrual dysphoric disorders. Contradictory, another study done in South India by Badiger S et al. 2012 found that male students (94\%) had more practice of self-medication than in female students (91\%). ${ }^{23}$ Out of 468 students in this study, SM was practiced by dentistry $111(93 \%)$ and medical students $156(91 \%)$ followed by pharmacy students 103 (88\%) from the first to fifth educational levels without significant differences between all levels. That means a medical background is not the basis of the SM practice as the rate very similar between the all-educational levels, the variation in socioeconomic characteristics may affect the practice of self-medication among participants. A study done at Mekelle University agreed with this finding, they found Self-medication was practiced by $32(42.67 \%)$ of medical students, 19 (76\%) for pharmacy students and $13(27.08 \%)$ of other health sciences 
students. ${ }^{15}$ Other studies inconsistent with our findings, they found that SM was more among senior students as they had better knowledge and greater awareness of the risks of self-medication that reflects the influence of medical training. ${ }^{11,24}$ However, in the current work, the most prevalent reasons for the SM among students were the mildness of the illness $(90 \%)$ and prior experience $(82 \%)$. Different reasons were reported in previous studies ranged from prior experience, availability of medications and the mildness of illness. ${ }^{14,15,22,25}$ Generally, Cough, common cold and headache were the most prevalent illnesses of subjected SM in the present study. These ailments have had the highest rate, thus accompanied by the use of analgesics (87\%), antipyretics (78\%) as well as cough and common cold preparations (82\%). The previous study done in King Saud University showed that analgesics (88.5\%) followed by flu treatment and antipyretics were the most drugs used as SM, which agreed with this study outcome. Additionally, another study conducted in South India found that antipyretics were the most commonly selfmedicated by the participants. ${ }^{21,22}$ According to another study, the most common antipyretic and analgesic agent used is Paracetamol. ${ }^{26}$ This drug and other common cold preparations are mostly dispensed in many countries as an over the counter drug (OTC). Finally, SM practice is a double-edged sword and needs proper medical information, health regulation, awareness of the use of that medications and restriction in selling especially for those containing narcotics or narcotic derivatives.

\section{CONCLUSION}

The self-medication practice was noticeable among health sciences undergraduate students in Sana'a city, this referred to the mildness of the illness and previous experience. The female showed a higher rate than males in SM practice in the current work. Cough, common cold and headache were the most prevalent illness in this study, for that analgesia, antipyretics and common cold medications were shown a higher rate of medications used.

\section{Limitations and strengths}

This study, conducted in two biggest private and governmental universities in Sana'a City, the outcomes of the current work was varied may be due to the small sample size that was taken from only these sectors. It is preferred to build up a complete overview of self-medication practice among health science students through taking the samples from different universities in either the Capital or the governorates. This study is the first one done in Yemen and the outcomes were given an overview of the practice of self-medication among the health science students that need awareness from the health authorities and academic staff as well as introducing the overusing hazardous of some medications as a weekly student's activities.

\section{ACKNOWLEDGEMENT}

The authors would like to thank all participants that voluntarily contributed to this study. Special thanks to the Department of Community Medicine especially Dr. Mahdi Al-Qrawani who validated the questionnaire and for everyone who helps to success this work.

\section{CONFLICT OF INTEREST}

The authors declare no conflict of interest.

\section{ABBREVIATIONS}

SM: Self-medication; UST: University of science and Technology; OTC: Over the counter drug.

\section{REFERENCES}

1. https://www.fda.gov/drugs/types-applications/drug-applications-over-counterotc-drugs (cited in 28-7-2019)

2. Organization $\mathrm{WH}$, The Role of the pharmacist in self-care and self-medication: report of the $4^{\text {th }}$ WHO Consultative Group on the Role of the Pharmacist, The Hague, The Netherlands, Geneva: World Health Organization. 1998. https:// apps.who.int/iris/handle/10665/65860

3. Industry WSM. WSMI Declaration on Self-Care and Self Medication. 2006. [cited 2019 April 14]; Available from:

4. Hussain S, Malik F, Hameed A, Ahmad S, Riaz H. Exploring health seeking behavior, medicine use and self medication in urban and rural Pakistan. Southern Med Review. 2010;3(2):32-5. https://pdfs.semanticscholar.org/7b80/4c02740df 02d5bb57e37bd42ba2515335b69.pdf

5. Hughe CM, McElnay JC, Fleming GF. Benefits and risks of self medication. Drug safety. 2001;24(14):1027-37. https://link.springer.com/article/10.2165/00002018-200124140-00002

6. Organizatio WH, Guidelines for the regulatory assessment of Medicinal Products for use in self-medication, Geneva: World Health Organization. 2000;31. https://apps.who.int/iris/handle/10665/66154

7. Lukovic JA, Miletic V, Pekmezovic T, Trajkovic G, Ratkovic N, Aleksic D, et al. Self-medication practices and risk factors for self-medication among medical students in Belgrade, Serbia. PLoS One. 2014:9(12):e1146444.https://www. ncbi.nlm.nih.gov/pubmed/25503967

8. Okyay RA, Erdoğan A. Self-medication practices and rational drug use habits among university students: A cross-sectional study from Kahramanmaraş, Turkey. Peer J. 2017;5:e3990. https://scinapse.io/papers/2765109788

9. Klemenc-Keti Z, Hladnik Z, Kersnik J. Self-medication among healthcare and non healthcare students at University of Ljubljana, Slovenia. Medi Princip and Practice. 2010;19(5):395-401. https://www.ncbi.nlm.nih.gov/pubmed/20639665

10. Aba S, Amelo W. Assessment of Self-medication practices among medical, pharmacy, health science students in Gondar University, Ethiopia. J of Young Pharmacists. 2010;2(3):306-10. https://www.ncbi.nlm.nih.gov/pmc/articles/ PMC2964771

11. Sontakke SD, Bajait CS, Pimpalkhute SA, Jaiswal KM, Jaiswal SR. Comparative study of evaluation of self-medication practices in first and third year medical students. Int J Biol Med Res. 2011;2(2):561-4. https://pdfs.semanticscholar.org/ 1fdf/72d9c3dfa2bdd1dabb49948efe2d088eee74

12. James H, Handu SS, AlKhaja KA, Otoom S. Sequeira RP5 Evaluation of the knowledge, attitude and practice of self-medication among first-year medical students. Medi Princip and Practice. 2006;15(4):270-5. https://www.scirp.org/ (S(i43dyn45teexjx455qlt3d2q))/.../ReferencesPapers.aspx?

13. Belkina T, AlWarafi A, Hussein EE, Tadjieva N, Kubena A, Vlcek J. Antibiotic use and knowledge in the community of Yemen, Saudi Arabiad Uzbekistan. J Infect Dev Ctries. 2014;8(4):424-9. https://www.ncbi.nlm.nih.gov/pmc/articles/ PMC4980922

14. Abdi A, Faraji A, Dehghan F, Khatony A. Prevalence of self-medication practice among health sciences students in Kermanshah, Iran. BMC Pharmacology and Toxicology. 2018;19(1):36. https://www.ncbi.nlm.nih.gov/pmc/articles/ PMC6029137/

15. Gutema G, Gadisa D, Kidanemariam Z, Berhe D, Berhe A, Hadera M, et al. Self-medication practices among health sciences students: The case of $\mathrm{Me}$ kelle University. App Pharm Sci. 2011;1(10):183-9. https://link.springer.com/article/10.1186/s40360-018-0205-6

16. ALbawani S, Bin HY, Abd-aziz N, Gnanasan SH. Self-medication practice among consumers in Sana'a City. Int J Pharm Pharm Sci. 2016;8(10):119-24. https:// innovareacademics.in/journals/index.php/ijpps/article/view/12748

17. ElEz N, Ez-Elarab H. Knowledge, attitude and practice of medical students towards self medication at Ain Shams University, Egypt. J Prev Med Hygiene. 2011;52(4):196-200. https://www.ncbi.nlm.nih.gov/pubmed/22442925

18. Zafar SN, Syed R, Waqar S, Zubairi AJ, Vaqar T, Shaikh M, et al. Self-medication amongst university students of Karachi: Prevalence, knowledge and attitudes. J Pak Med Assoc. 2008;58(4):214-7. https://www.ncbi.nlm.nih.gov/ pubmed/18655436

19. DaSilva MGC, Soares MCF Muccillo-Baisch AL. Self-medication in university students from the city of Rio Grande, Brazil. BMC Public Health. 2012;12:339. https://www.ncbi.nlm.nih.gov/pubmed/22568959

20. AlRaddadi KK, Barakeh R, AlRefaie S, AlYahya L, Adosary M, Alyahya K. Determinants of self-medication among undergraduate students at King Saud University: Knowledge, attitude and practice. J Health Spec. 2017;5(2):95-101. https://www.researchgate.net/.../316433301_

21. Kayalvizhi S, Senapathi R. Evaluation of the perception, attitude and practice of self medication among business students in 3 select cities, South India. IJEIMS. 2010;1(3):40-4. https://pdfs.semanticscholar.org/84de/11896b245b6ef baf2cab70b39ed1ed96526e

22. Klemenc-Ketiš Z, Hladnik Ž, Kersnik J. A cross sectional study of sex differences in self-medication practices among university students in Slovenia. Collegium Antropologicum. 2011;35(2):329-34. https://www.ncbi.nlm.nih.gov/ 
pubmed/21755698

23. Badiger S, Kundapur R, Jain A, Kumar A, Pattanshetty S, Thakolkaran N, et al. Self-medication patterns among medical students in South India. Austra Med J. 2012;5(4):217-20. https://www.ncbi.nlm.nih.gov/pubmed/22848313

24. James H, Handu SS, Khaja KA, Sequeira RP. Influence of medical training on self-medication by students. Int J Clin Pharm Th. 2008;46(1):23-9. https://www. ncbi.nlm.nih.gov/pubmed/18218294
25. Shveta S, Jagmohan S. A study of self-medication pattern in Punjab. IJOPP. 2011;4(2):43-6. https://pdfs.semanticscholar.org/1531/56a63a338d3106bd02b2 e77711f637c98e7e

26. Limaye D, Limaye V, Krause G, Fortwenge G. A Systematic Review of the Literature to Assess Selfmedication Practices. Ann Med Health Sci Res. 2017;7(1). https://www.amhsr.org/.../a-systematic-review-of-the-literature-to- assess-selfmedicatio.

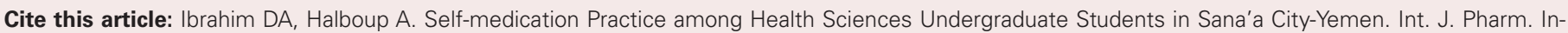
vestigation. 2019;9(2):80-4. 